Int. J. Electrochem. Sci., 12 (2017) $6788-6800$

\title{
Corrosion Behavior and Structure of Plasma Electrolytic Oxidation Coated Aluminum Alloy
}

\author{
Y. Zhang ${ }^{1,2}$,W. Fan ${ }^{1}$, H.Q. Du ${ }^{1}$, Y.W. Zhao ${ }^{2, *}$ \\ ${ }^{1}$ School of Mechanical Engineering, Zhejiang Industry Polytechnic College, Shaoxing 312000,China; \\ ${ }^{2}$ Key Lab of E\&M, Ministry of Education\&Zhejiang Province, Zhejiang University of Technology, \\ Hangzhou 310014, China \\ E-mail: zyzjipc@126.com
}

doi: 1020964/2017.07.70

Received: 18 March 2017 / Accepted: 11 May 2017 / Published: 12 June 2017

In this study, the plasma electrolytic oxidation (PEO) coatings were formed on aluminum alloy in a cheap and convenient electrolyte. The effect of different current densities, i.e., $5 \mathrm{~A} / \mathrm{dm}^{2}, 10 \mathrm{~A} / \mathrm{dm}^{2}, 15$ $\mathrm{A} / \mathrm{dm}^{2}$ and $20 \mathrm{~A} / \mathrm{dm}^{2}$ on microstructure and corrosion behavior of coatings was comprehensively studied by scanning electron microscopy (SEM), stereoscopic microscopy, potentiodynamic polarization and electrochemical impedance spectroscopy (EIS) tests, respectively. It was found that the pore density decreased and the pore size increased with the increment of the applied current density. The X-ray diffraction (XRD) results showed that the coatings were only composed of $\alpha-\mathrm{Al}_{2} \mathrm{O}_{3}$ and $\gamma-\mathrm{Al}_{2} \mathrm{O}_{3}$. Potentiodynamic polarization test proved that the coating formed under the current density of $10 \mathrm{~A} / \mathrm{dm}^{2}$ showed the best anti-corrosion property. The long time EIS test showed that the coating formed under the current density of $10 \mathrm{~A} / \mathrm{dm}^{2}$ was capable to protect the aluminum alloy substrate after long time of immersion in $0.59 \mathrm{M} \mathrm{NaCl}$ solution, which confirmed well with the salt solution immersion test results in $2 \mathrm{M} \mathrm{NaCl}$ solution.

Keywords: Aluminum alloy; Plasma electrolytic oxidation (PEO); Current density; Structure; Corrosion resistance

\section{FULL TEXT}

(C) 2017 The Authors. Published by ESG (www.electrochemsci.org). This article is an open access article distributed under the terms and conditions of the Creative Commons Attribution license (http://creativecommons.org/licenses/by/4.0/). 
